\title{
MANIFESTACIONES DE LA RELIGIOSIDAD POPULAR EN TORNO A TRES IMÁGENES MARIANAS ORIGINARIAS. LA UNIDAD DEL RITUAL Y LA DIVERSIDAD FORMAL
}

\author{
Magdalena Vences Vidal*
}

RESUMEN: El artículo aborda el tema de la religiosidad popular a través del culto a tres imágenes marianas durante la Colonia: la Virgen de Guadalupe del Tepeyac (México), la Virgen del Rosario de Chiquinquirá (Colombia) y la Virgen de El Quinche (Ecuador). Estos tres casos hispanoamericanos son referente para que la autora reflexione, en la primera parte, sobre los conceptos utilizados para explicar el comportamiento religioso del pueblo —-principalmente la religiosidad, lo popular y lo oficial-; a partir del análisis de autores españoles que tratan estos conceptos, expone el papel que desempeñaron las manifestaciones colectivas externas en torno a las imágenes y fenómenos como el milagro y la fiesta. En la segunda parte, la autora describe los medios usados para afianzar y expandir el culto a las imágenes sagradas, en donde destaca el importante papel que tuvieron los traslados de las imágenes y sus reproducciones plásticas. Finalmente, analiza los conceptos de cultura y del barroco.

Palabras clave: Virgen María, Religiosidad, Procesión, Cultura Barroca, Ritual.

ABSTRACT: The article deals about the popular religiosity through the cult to three Marian images during the Colony: "The Virgen de Guadalupe del Tepeyac" (Mexico), The "Virgen del Rosario de Chiquinquirá" (Colombia) and "The Virgen de El Quinche" (Ecuador). This three Hispanic-American cases are a reference the author uses to reflect, in the first part, about the concept used to explain the religious behavior of the people -mainly the religiosity, the popular and the official-; through Spanish authors which study those concepts, exposes the roll the external collective manifestations had about the images and phenomena like miracles and celebrations. In the second part, the author describes the means used to strengthen and to expand the cult to sacred images and she highlights the important roll that the translation of those images and their reproductions had. Finally she analyses the concepts of culture and baroque.

KEY WORDS: Virgin Mary, Religiosity, Procession, Culture, Baroque, Ritual.

\footnotetext{
* Centro de Investigaciones sobre América Latina y el Caribe, UNAM (vences@servidor.unam.mx).
} 


\section{INTRODUCCIÓN}

Este artículo, acerca del culto externo manifestado por el hombre a las imágenes sagradas, está dirigido a reflexionar sobre determinados conceptos con los que se ha definido y calificado al comportamiento religioso del pueblo como: la religiosidad, lo popular y oficial, y la cultura barroca, que tuvo su concreción en el mundo colonial americano desde el siglo XVI. Este comportamiento social es en buena parte la base de las formas y fórmulas o medios de manifestación religiosa que han llegado a nuestros días a través del culto que el pueblo tiene a las más famosas devociones y a las tenidas por imágenes milagrosas, mediante las que se ha "recuperado" el uso de espacios que alguna vez fueron públicos.

En esta sección me valgo de una selección de autores españoles, sus ideas y ejemplos ibéricos con los que establezco una afinidad de lo sucedido en Hispanoamérica, partiendo de la afirmación de que la transmisión de la cultura occidental europea se llevó a cabo a través del proceso de expansión de la monarquía hispana. Paso después a resaltar el uso de un par de medios de difusión de la imagen sagrada: los traslados y las recreaciones plásticas que se constituyeron en memoria viva y futura de acontecimientos del pasado, elementos además de identidad; cierro al final con una decantada cita de los conceptos: cultura y barroco.

Este acercamiento a la comprensión de la cultura cristiana católica barroca de América hispana tiene el objetivo de recuperar fragmentos de la historia de una tradición y prácticas o modos de vivir la Religión, ${ }^{1}$ que se dieron — con sus peculiaridades - en tres focos de devoción mariana: la Virgen de Guadalupe (México), la Virgen de Chiquinquirá (Colombia) y la Virgen de El Quinche (Ecuador). Principalmente expongo ejemplos de vehículos o mecanismos comunes del comportamiento religioso desde la segunda mitad del siglo XVI, cuya pervivencia y uso fue fortalecido en el

\footnotetext{
${ }^{1}$ Religión entendida como "el conjunto de dogmas y bases doctrinales; lo que se debe creer y saber", José Domínguez León, "Bases metodológicas para el estudio de la religiosidad popular andaluza”, en María de Jesús Buxo Álvarez Santaló y Salvador Rodríguez Becerra [coords.], La religiosidad popular, Barcelona, Anthropos, vol.1, p.147.
} 
siglo XVII a través del arte en el marco ideológico del dirigismo contrarreformista de los monarcas de la Casa de Austria.

Comparto plenamente la definición que han hecho especialistas en la materia, como Rodríguez Becerra y Sánchez Herrero, acerca de que la religiosidad es la concreción de la religión en el hombre en su vínculo con lo divino, en busca de una serie de respuestas a la pregunta: "cómo el pueblo siente y manifiesta su religión, su relación con la divinidad". ${ }^{2} \mathrm{De}$ modo que esta práctica popular o del pueblo, incluyente de todo individuo, es la manifestación de "una búsqueda de relaciones con lo divino", en pos de un contacto más directo con la divinidad, con los santos y a través de la intercesora del hombre - la Virgen María - para que éstos rueguen al Dios-Hijo y éste medie ante Dios Padre por la salvación del ánima. Dicho comportamiento sostiene una relación, ineludible, con la oficialidad de la Iglesia a través de sus prelados y de las autoridades seglares, de las orientaciones dogmáticas y normas establecidas en los textos emanados de los concilios provinciales y de los sínodos diocesanos celebrados en Hispanoamérica en el marco de los decretos del ecuménico Concilio de Trento, donde se afianzó el concepto de "Tradición de la Iglesia: las Escrituras y los Santos Padres", tradición invocada ya desde el año 787 en el Segundo Concilio de Nicea. ${ }^{3}$ Feligresía e Iglesia en un objetivo común, rendir culto a Dios, a la Virgen, a los santos y a las santas Reliquias en las iglesias, santuarios, capillas, altares.

En los cultos se plasma el "concepto de religiosidad o de creencia [y se define como] el conjunto de las interrelaciones de todos aquellos elementos conectados con ella". ${ }^{4}$ De modo que, la religiosidad se expresa o manifiesta en creencias concretas e impregnadas de rituales en un sis-

2 José Sánchez Herrero, "Religiosidad cristiana popular andaluza durante la Edad Media”, en ibid., vol. 1, p. 105, apud Real Diccionario de la Real Academia. Véase Salvador Rodríguez Becerra, "Introducción”, en ibid., vol. 1, p. 10.

${ }^{3}$ Nelly Sigaut, José Juárez. Recursos y discursos del arte de pintar, Milán, Landucci Editores y Leonardo Internacional, 2002, pp. 26 y 27.

${ }^{4}$ Jorge Antonio Rincón Mirón, "Nuevas perspectivas de estudio sobre la religiosidad medieval”, en Álvarez Santaló y Rodríguez Becerra, op. cit., vol. 1, pp. 136 y 137. 
tema de prácticas encaminadas a expresar un sentimiento piadoso o de piedad en torno a determinadas imágenes sagradas a las que se venera en espacios geográficos, político-culturales y económicos significativos. Dado este carácter de conexión de factores hay en el ritual una polisemia de valores, ya que "no sólo comunican mensajes relacionados con lo sobrenatural, sino también con lo económico, lo social, lo lúdico, la identidad cultural y todo el sistema cultural". 5 Todo este conjunto estuvo presente en el establecimiento y desarrollo de los tres cultos marianos aquí comentados, generadores de identidades y poderío económico regional, cuyas imágenes ondearon como estandartes en la construcción de sólidos caminos de las naciones formadas después de consumados los procesos de independencia.

En las manifestaciones externas colectivas como en los interiores de las iglesias se reprodujo el orden social de los individuos y grupos de las diversas comunidades hispanoamericanas; es a través del mecanismo de las primeras con las que se impulsó el reconocimiento de un culto, su extensión y preeminencia en otras regiones. Los medios fueron la romería individual y después colectiva al santuario - hecha a raíz de la "fama" de la advocación por su origen milagroso, por sus prodigios o señales sobrenaturales - ; la procesión local fue de circunscripción delimitada, en el recuadro de la población, en la misma categoría se encuentra la rogativa y la fiesta de la imagen tutelar, en tanto que los mecanismos más contundentes para dar a conocer a la imagen fue, por un lado, el traslado de la misma de su núcleo de devoción a otros territorios en aras de sacralizarlo y de extender el área de influencia y de beneficio para el afianzamiento del culto, por otro la multiplicación de las copias plásticas destinadas a conquistar creyentes y a generar cofradías, así como los lienzos memorativos de los favores a la población y a particulares que revistieron los muros interiores de los santuarios barrocos.

Respecto al término popular hay múltiples interpretaciones y aplicaciones según la época o la manifestación específica de la que se hable y

${ }^{5}$ Rodríguez, Introducción, en ibid., p. 9. 
los agentes que intervienen en ella. Una explicación que comparto es la que, como otros autores, anota García García: "La adjetivación de la religión como popular hace referencia a otro tipo de religiosidad que, por lo general, es tipificada de oficial. Ambas se entremezclan, coexisten de forma más o menos diferenciada". ${ }^{6}$ En uno y en otro caso hay un vínculo, unos procesos de convivencia. Para este autor la relación establecida entre ambas "es una cuestión de control social", intereses individuales o bien de grupo, y "es en la confrontación de estos sistemas de intereses, gestados a veces en un largo proceso histórico, donde debe analizarse la relación entre la religiosidad oficial y la popular."7

Esta diferenciación, en los ejemplos hispanoamericanos que me ocupan, se advierte en el contenido de las descripciones de los traslados y las procesiones, donde se describe el orden de quienes trasladan y quienes reciben; donde se pone énfasis en cómo a diferencia de los españoles, los indios y castas manifestaban su forma de religiosidad. Aunque todos ellos de manera conjunta participaron en un objetivo común: la búsqueda de reconocimiento de una imagen sagrada a través de sus formas de devoción y demostración de respeto, mediante conductas ejemplares en el marco de una buena gama de parafernalia sensible — de herencia medieval pero también enriquecida con el aporte del territorio y las comunidades locales - Estas formas materiales del culto externo establecidas por la tradición fueron respaldadas oficialmente y sopesadas en el tamiz

${ }^{6}$ José Luis García García, "El contexto de la religiosidad popular", en Álvarez Santaló, op. cit., vol. 1, p. 19, especialmente se refiere al término en relación a las reminiscencias de antiguos sistemas de creencias y prácticas en la religión dominante. Sánchez Herrero, op. cit., p. 107, apud Maldonado, subraya que "hay una relación dialéctica entre lo popular y lo no popular (llámese oficial, institucional, etc.), es muy difícil establecer qué fue primero en un marco histórico-temporal o diacrónico". Por otra parte Antonio García y García, "Religiosidad popular y derecho canónico", en Álvarez Santaló, op. cit., vol. 1, pp. 231 y 232, expone la problemática entre la separación y la cercanía de ambas religiosidades que "con frecuencia se yuxtaponen [...], se anteponen, se superponen y hasta se contraponen".

${ }^{7}$ García García, op . cit., vol. 1, p. 25. En relación a la religiosidad contemporánea, véase Domínguez, op. cit., vol. 1, pp.145 y ss., se sopesan los valores cuantitativos y cualitativos como categorías para la definición de "popular". 
de las discusiones teóricas sobre la decencia y el decoro en relación al manejo y presentación de la imagen sagrada. Mediante los trayectos se dio pie a la organización de sistemas sociales y económicos que garantizaran el sostenimiento del culto, a través de las donaciones de materiales de todo tipo - donde el factor emulación entre individuos y grupos plasmó materialmente sus resultados -; otro elemento fue auspiciar la integración a las cofradías, de papel fundamental en el sostén del culto y en la búsqueda del bien común de los congregados. ${ }^{8}$

En nuestra época las expresiones externas del sentimiento religioso han quedado al margen de la vida cotidiana desde los cambios radicales de los últimos años del siglo XIX. Rodríguez Becerra pone el dedo en la llaga al plantear una realidad que en buena medida se comprueba aún ahora, ante la disminución de la asistencia sacramental se percibe un mayor interés a la concurrencia de las celebraciones públicas, en las que en buena medida se participa como espectador: "hemos sido testigos de un incremento o intensificación de determinadas formas de expresión de la religión, conocidas como populares, en perjuicio de otros rituales, considerados centrales en el cristianismo, tales como la misa."9

Entre la conducta referida y la manifestación de la religiosidad barroca contrarreformista hay una gran distancia. A la asistencia del sacramento del Altar, en el santuario, se instaba al rezo del rosario, a efectuar novenas, a participar de la normatividad para alcanzar los privilegios de las indulgencias; ya que cuando se visita una imagen sagrada en su santuario y se está frente a ella — con velos y sin ellos — se cumple el encuentro con el misterio o la divinidad. Por ejemplo, el padre Florencia (1688) describe este uso en relación con la Virgen de Guadalupe cuando

\footnotetext{
${ }^{8}$ Véase Magdalena Vences Vidal, "Romerías y sacralización del espacio en Boyacá, Colombia, siglo XVI", en Latinoamérica. Revista de Estudios Latinoamericanos, núm. 37, (2003/2), México, CCydEL-UnAM, pp. 123-143; de la misma autora "La Virgen de Chiquinquirá y la construcción de una identidad regional en el Nuevo Reino de Granada”, en Verónica Oikión Solano [ed.], Historia, nación y región, México, El Colegio de Michoacán, 2007, vol. 1, pp. 315-349.

${ }^{9}$ Rodríguez Becerra, op. cit., pp. 8 y 9.
} 
su imagen estaba en el retablo que lució en la iglesia que mandó hacer el arzobispo Juan Pérez de la Serna, al respecto detalla el autor jesuita:

está colocada la santa imagen debajo de puerta y llave: y es la puerta de dos bellas lunas de cristal, tan grandes, que cogen la imagen de pies a cabeza de más de dos ricos velos o cortinas, con que está retirada a la vista, cuando no se dice misa en el altar mayor, o cuando no hay personas de respeto, que para velar ante ella, piden se corran; y entonces se encienden las luces del altar para mayor adorno y reverencia. ${ }^{10}$

Sin duda como parte de la tradición cristiana, el incentivo que convocó en general a la feligresía fue dar información de lo extraordinario o maravilloso - la manifestación de la divinidad y la expresión de su poder - así el fenómeno de la percepción de lo sobrenatural también hizo su aparición. El milagro en sí y el reconocimiento de los favores concedidos fueron los medios que se utilizaron para afianzar la devoción particular en estrecha relación con el prestigio de una imagen sobre otras, o junto a otras, en cualquier caso representativas de una comunidad o de grupos adscritos a un territorio político y geográfico. La feligresía echó mano de una serie de vínculos con la divinidad a través de las advocaciones marianas, cristológicas, de algunos santos y aun arcángeles. El milagro es entendido como "la concreción positiva de un acto de fe por el que se vinculan el beneficiario de una gracia y, en ocasiones, el inductor de la invocación con el santo que canaliza la concesión". ${ }^{11}$ Es por ello que uno de los canales de estudio de la religiosidad medieval europea ha sido

${ }^{10}$ Francisco de Florencia, La estrella del norte, en Ernesto de la Torre Villar y Ramiro Navarro de Anda, Testimonios históricos guadalupanos, México, FCE, 1982, pp. 359 y 376-377. Sobre el uso de los velos en relación a la Virgen de Chiquinquirá, véase Magdalena Vences Vidal, "La orden de predicadores y el marianismo de la monarquía española. El culto a la Virgen de Chiquinquirá”, ponencia presentada en el IX Congreso Internacional de Historiadores dominicos [en prensa].

11 Ángela Muñoz Fernández, "El milagro como testimonio histórico. Propuesta de una metodología para el estudio de la religiosidad popular”, en Álvarez Santaló, op. cit., vol. 1, p. 177, no obstante su naturaleza se considera un objetivo central de estudio por ser "uno de los rasgos más característicos del nivel religioso que nos ocupa", el de la religiosidad popular. 
la utilización del milagro como fuente histórica. ${ }^{12}$ Dado el carácter de relación entre la divinidad y el hombre, en la que lo sobrenatural satisface la cercanía con lo intangible y acorta la distancia entre ambos.

De modo similar, los casos latinoamericanos también han sido sometidos a este tipo de análisis, entre otras metodologías, con la finalidad de aproximarse a una explicación del hecho religioso, social y cultural. Muñoz propone que en la perspectiva del milagro, como información, se han de considerar dos aspectos básicos y diferenciados: uno, "el suceso per sé, inserto en una tradicional cultural"; dos, "el testimonio de este suceso", o de las actitudes, emociones y construcción de medios materiales y sensibles que buscaron comprobar y difundir las manifestaciones sobrenaturales. Ambas consideraciones las he abordado en otros escritos sobre la religiosidad en torno a las advocaciones marianas que me ocupan, en los que se plantea cómo a partir de las hierofanías y milagros, la Iglesia y la feligresía interactuaron para el establecimiento y consolidación de los cultos. Es pues, importante utilizar los testimonios de prodigios como fuentes para la construcción histórica de las manifestaciones religiosas populares. La impresión y la explicación del milagro son distintas para los individuos. Acudo a la interpretación de Muñoz ${ }^{13}$ para exponer esta diferencia:

la piedad popular enjuicia y entiende el milagro desde una base de percepción, esencialmente emotiva, adaptable, de manera funcional, a un vasto conjunto de necesidades de toda índole. Mediante la intervención de lo maravilloso o lo extraordinario, estas necesidades pueden ser satisfechas. El santo hace milagros porque es santo, así se resume la explicación popular. Como contrapartida, las posturas eclesiásticas oficiales se sitúan en otras coordenadas de racionalización del hecho. El milagro es también una prueba, pero subordinada o asociada a otras variables constitutivas de la santidad, la virtus. Más apegada a la tradición dogmática, la Iglesia oficial inserta toda consideración sobre el fenómeno en un sistema de "racionalidad" teológica. En esencia, el milagro es un testimonio histórico por el cual

12 Ibid., pp. 164-185.

${ }^{13}$ Ibid., p. 169, apud R. Manselli. 
Dios certifica la santidad, indemostrable por ningún otro conducto. Pero esta certificación se opera sobre una realidad preexistente: la virtud de obras y de pensamiento.

Estas formas de percepción son generadoras de dos canales de entendimiento y práctica de la religión, una denominada popular y la otra oficial o institucional, cuyos medios de expresión además de la misa y el sermón fueron las normatividades sinodales y diocesanas. La diferencia cultural de los receptores genera variadas emociones y prácticas de la religión, en el exterior e interior de las iglesias de veneración, son a su vez complementarias e incluyentes pues son la expresión de la iglesia y la comunidad heterogénea que es aglutinada - por una u otra forma de religiosidad - en el territorio donde se ha reconocido a una imagen sagrada como propia.

Hay que considerar que de modo similar al amplio arco cronológico del medioevo al barroco en Europa, en Hispanoamérica la gran mayoría de la población era analfabeta, excepción de los eclesiásticos y otros miembros de la sociedad, de modo tal que las narraciones se plasman en las artes plásticas, en el teatro y en la representación de dramas litúrgicos. Otra de las expresiones y mecanismos de la religiosidad popular es la fiesta, como el principal ejemplo de la manifestación externa de la religiosidad, es "la que mereció siempre mayor atención por parte del derecho canónico común;" ${ }^{14}$ y es a su vez, el espejo del orden social, ${ }^{15}$ como de la plasmación del prestigio y acciones del buen cristiano.

En un principio el festejo a las tres imágenes se amparó en las fiestas de la Virgen: la Candelaria, la Encarnación, la Visitación, la Asunción, la Natividad y la Concepción, más tarde estatuidas de guardar en los Concilios provinciales, unas para indígenas y otras para españoles. En la práctica, a dos de ellas se las festejó en el día de sus prodigios: 26 de di-

${ }^{14}$ García y García, op. cit., p. 232.

15 Antonio Rubial García, "Introducción" a Francisco de Florencia y Juan Antonio de Oviedo, Zodiaco mariano, México, Conaculta, Sello Bermejo, 1995, p. 23. 
ciembre (Chiquinquirá) y el 12 de diciembre (Tepeyac), y fue mucho después que se llegó a formalizar un día de fiesta especial con oficio propio. En el caso de Guadalupe, durante mucho tiempo los indios además la festejaron aparte y fue hasta 1754 que se estatuyó el 12 de diciembre, ${ }^{16}$ como rememoración del milagro de las rosas. En tanto que para la de Chiquinquirá, a la cual se le celebraba en el día de su renovación, fue hasta el 29 de julio de 1819 cuando se solicitó la concesión del oficio litúrgico en honor de la Virgen, y el 12 de abril de 1825 León XII concedió la fiesta litúrgica en honor de Chiquinquirá; más tarde, en 1829 el papa Pío VIII "aprobó el oficio de la Virgen" marcado en el santoral el 9 de julio. ${ }^{17}$ En esa ocasión también se obtuvo el reconocimiento de la Santa Sede de su patronazgo principal sobre la Arquidiócesis de Santafé. ${ }^{18}$ En tanto que a la Virgen de El Quinche se la festejó en el día de la Presentación de la Virgen al templo, desde el 21 de noviembre de 1594, con la finalidad de impulsar el restablecimiento de esa festividad. ${ }^{19}$

Andalucía y Castilla es el referente obligado para el mejor conocimiento e interpretación de las manifestaciones de la religiosidad en las tres regiones que me ocupan: México, Colombia y Ecuador; son dos de los centros político-religiosos y culturales protagónicos en la unión y expansión de la monarquía española. Andalucía prerromana, tardorromana

${ }^{16}$ Ivan Martínez, "El primer cabildo de Guadalupe”, en Nelly Sigaut [ed.], Guadalupe arte y liturgia. La sillería de coro de la colegiata, México, El Colegio de MichoacánMuseo de la Basílica de Guadalupe-Insigne y Nacional Basílica de Santa María de Guadalupe, 2006, vol. 1, p. 112.

${ }^{17}$ Víctor Raúl Rojas Peña, La coronación de la Virgen de Chiquinquirá, Obras civiles y sagradas. El entredicho 1865-1919, Santafé de Bogotá, ABC, 2000 (Biblioteca de Autores Chiquinquireños), p. 185. Vicente María Cornejo (OP) y Andrés Mesanza (OP), Historia de la milagrosa imagen de Nuestra Señora del Rosario de Chiquinquirá, de su ciudad y su convento, Bogotá, Escuela Tipográfica Salesiana, 1919, p. 100. Alberto Ariza, "Apostillas a la historia de Nuestra Señora de Chiquinquirá", Boletín de Historia y Antigüedades, vol. LVI, núms. 651 a 653, Bogotá, enero-marzo, 1969, pp. 90-92, el $1^{\circ}$ de septiembre de 1760 la doctrina de Chiquinquirá se elevó a parroquia.

${ }^{18}$ Cornejo y Mesanza, op. cit., pp.100 y 101. Ariza, op. cit., p. 92.

${ }^{19}$ Magdalena Vences Vidal, "Un triunfo de la contrarreforma: la devoción a Nuestra Señora de la Presentación en Ecuador”, Historias 54, Revista de la Dirección de Estudios Históricos del INAH, enero-abril, 2003, pp. 83-100. 
y visigoda, musulmana, mozárabe y castellana. ${ }^{20}$ Suma de culturas portadas, en distintos rangos, por aquéllos que pasaron a residir en Hispanoamérica, y que a su vez coexistieron con otras tradiciones culturales americanas. Andalucía-Castilla por lengua e instituciones, por manifestaciones artísticas, culturales y de religiosidad, en donde es importante la diversidad de expresiones correspondiente a la procedencia y educación.

\section{LOS TRASLADOS, LOS “EVANGELISTAS” Y LOS “APÓSTOLES” DE LAS IMÁ- GENES, LA MEMORIA VISUAL}

Retomo aquí una breve mención de alguna de las informaciones sobre el estado de la devoción de la Virgen de Guadalupe en el siglo XVI, entre españoles e indígenas, para después citar ejemplos de los medios de religiosidad que fueron plasmados en lienzos de pintura del siglo XVII y que son memoria de los caminos del hombre en busca de una relación cercana y estrecha con lo divino. Las pinturas están enfocadas a constituir un testimonio visual de tan antiguos sucesos y que se suman a otros canales de consolidación del culto guadalupano, invocados por los crio1los. Así, los muros interiores de la Basílica de Guadalupe, como los de Chiquinquirá y El Quinche, estuvieron "vestidos" de las pruebas de los beneficios obrados por las imágenes originarias desde el mismo siglo de la conquista y evangelización.

La devoción a la Virgen de Guadalupe y la existencia entre 1555 y 1556 de una ermita dedicada a la misma está respaldada por las menciones en un grupo de documentos. El contenido parcial de uno de ellos fue dado a conocer ya hace tiempo por Francisco de la Maza, se trata de una carta del 23 de septiembre de 1575 del virrey Martín Enríquez, dirigida al monarca español, en ella se afirma que la imagen honrada en la ermita es la misma que se veneraba en la iglesia, cuya devoción se había incrementado por la difusión que hubo acerca del favor que hizo a un gana-

${ }^{20}$ Sánchez Herrero, “Algunos elementos de la religiosidad cristiana popular andaluza durante la Edad Media”, en Álvarez Santaló, op. cit., vol. 1, pp. 300-302. 
dero. La misiva citada refiere la importante respuesta a ese núcleo sagrado, pues ya se registra la fundación de una cofradía

en la cual dicen habrá cuatrocientos cofrades y de las limosnas se labró la iglesia y el edificio todo que se ha hecho, y se ha comprado alguna renta, y lo que parece que ahora tiene y lo que se saca de limosnas envío ahí, sacado del libro de los mayordomos de las últimas cuentas que se les tomaron y la claridad que más se entendiere se enviará a vuestra majestad. ${ }^{21}$

Acerca de esta primera etapa del culto entre españoles e indígenas recurro a lo registrado por Chimalpahin respecto a los sucesos del año 1556, pues fue importante entre los indígenas, al respecto dice: "entonces ocurrió la aparición, dicho sea con respeto, de nuestra querida madre, Sancta María de Guadalupe en el Tepeyácac". ${ }^{22}$ Esta información está puesta de relieve entre otras advocaciones marianas estimadas por los indios, dada su participación en las fiestas de guardar y en el desarrollo de sus cultos. Referente obligado para ese mismo año es la controversia entre el arzobispo fray Alonso de Montúfar (OP) y el provincial franciscano fray Francisco de Bustamente, respecto al culto de la imagen en el Tepeyac: de lo que se derivó la famosa Información jurídica de 1566; el prelado dominico argumentó ante la crítica del franciscano Bustamante, que "no se hace reverencia a la tabla [i?] ni a la pintura, sino a la imagen de Nuestra Señora por razón de lo que representa". ${ }^{23}$ Montúfar en calidad

${ }^{21}$ Francisco de la Maza, El guadalupanismo mexicano, México, Porrúa y Obregón, 1953 (México y lo mexicano, 17), p. 19. Mina Ramírez Montes, Ars Novae Hispaniae, antología documental del Archivo General de Indias, México, IIE-UNAM, 2005, t. 1, p. 72, carta del 23 de septiembre de 1575, es respuesta a la cédula real emitida en El Escorial el 15 de mayo de 1575, en otro fragmento el virrey expuso que no era conveniente fundar convento, mucho menos una parroquia, ya sea para indios o para españoles, sólo un clérigo encargado de impartir el sacramento de la confesión a los devotos, en tanto que las limosnas se invertirían en el Hospital Real de los indios o dotación de matrimonios de huérfanas.

${ }^{22}$ Relaciones originales de Chalco Amaquemecan por Francisco de San Antón Muñón Chimalpahin Cuauhtlehuanitzin, paleografía, trad. y glosa de Silvia Rendón, MéxicoBuenos Aires, FCE, 1965, p. 264.

${ }^{23}$ De la Maza, op. cit., p. 14. Toda esta información redondea y amplía las afirmaciones de una larga lista de autores: Torre Villar y Navarro, O'Gorman, Noguez, Godínez; véase Sandoval op. cit., vol. 1, pp. 153-177. 
de máximo prelado, representante de la monarquía y patrono de la Iglesia en Nueva España, respaldó el naciente culto construido en las afueras de la ciudad de México, con todo el protocolo jurídico sobre el caso.

Este respaldo es una característica común a los otros dos casos que me ocupan; así, en los últimos años del siglo XVI en el nuevo Reino de Granada, el arzobispo fray Luis Zapata de Cárdenas (OFM) actuó con rigor sobre el origen del culto a la Virgen de Chiquinquirá, como expresión del acatamiento a las normatividades tridentinas, del mismo modo ante una situación diferente, fray Luis López de Solís inspeccionó en la Diócesis de Quito el estado de la devoción a la Virgen de Oyacachi (Quinche). ${ }^{24}$

En la "Memoria de templos, monasterios, ermitas y cofradías de la ciudad de México", ${ }^{25}$ se cita la ermita de Guadalupe donde se dice misa y que para entonces era una de las 18 cofradías existentes, menos una, todas las demás se sustentaban de limosnas. Además de la integración numerosa de la cofradía y de las cuantiosas limosnas administradas por los mayordomos, hicieron su aparición las indulgencias especiales que se concedían a través de la advocación originaria novohispana, la emisión de éstas fue más temprana de lo que se hubiera pensado, pues en 1575 el pontífice Gregorio XIII prorrogó las “que en años anteriores había otorgado la santa Sede a la ermita guadalupana". ${ }^{26}$ En tanto que las primeras en Chiquinquirá fueron emitidas en 1596 — casi diez años después del año oficial de la manifestación prodigiosa de la imagen — cuyos beneficiarios serían los devotos y peregrinos que hicieran la visita anual y rezaran a la imagen novogranadina (del mismo carácter fueron concedidas a los miembros de la cofradía del Rosario en 1613 y 1644). En ambos casos como medidas oficiales para afianzar la devoción entre

${ }^{24}$ Sobre la Virgen de El Quinche véase Magdalena Vences Vidal, "Una imagen mariana entre los indígenas de Ecuador: de Oyacachi al Quinche", Latinoamérica. Revista de Estudios Latinoamericanos, núm. 33, México, CCyDEL-UnAM, 2002, pp. 25-62.

${ }^{25}$ Ramírez, op. cit., pp. 65-67, ciudad de México, 15 de septiembre de 1575; la información sobre la ermita de Guadalupe y el destino de la renta asignada en una carta que el virrey Martín Enríquez envió al rey, t. 1, p. 71, "Relación de cartas [...], 21 de septiembre de 1575 .

${ }^{26}$ Sigaut, José Juárez..., p. 211, véase nota 2. 
otros incrementos, pero también resultado de las instancias de los promotores de sus cultos ante la sede pontificia.

Es indudable que para entonces, en el último cuarto del siglo XVI, en el caso mexicano y en el colombiano ya había un grupo considerable de devotos españoles e indígenas, con vistas a involucrar a toda una región y al virreinato, que se lograría en buena medida hasta el siglo XVIII. Este primer momento fue el de la construcción de las leyendas en torno a los favores concedidos y el reconocimiento de la imagen como propia, fueron los largos años de diseminación del culto. El destino de la abundancia de limosnas en el caso de Guadalupe fue propuesto para canalizarlo a una obra pía, ya sea al Hospital Real de indios o la dotación de huérfanas, como otros de los medios menesterosos y ejemplares de propagación del culto a la imagen. En poco más de doce años, en Chiquinquirá operó de modo similar: la fama de la imagen prodigiosa, la recolección de limosnas para construirle una capilla, la organización de la cofradía, la designación de los mayordomos, el libro de cuentas con el registro de los donantes, etc. En toda esta obra mucho se hizo y resultó de las prácticas externas de vivir la religión.

Como bien se sabe las fuentes del culto a Guadalupe del Tepeyac exhiben diferenciadamente a dos destinatarios: tal es el Nican Mopohua cuyo relato en náhuatl está dirigido a los indígenas, atribuido a Antonio Valeriano y publicado en $1648 .{ }^{27}$ En tanto que a la del bachiller criollo, Miguel Sánchez, correspondió la difusión de los relatos entre los criollos y los mestizos mediante esta obra simbólica sobre la "tradición establecida del culto guadalupano", ${ }^{28}$ del año 1648. Éste es el primero de los cuatro "evangelistas" o autores que escribieron en el siglo XVII sobre los orígenes de la imagen de nuestra señora de Guadalupe; el primero seguido de la obra en

\footnotetext{
${ }^{27}$ Edmundo O'Gorman, Destierro de sombras, luz en el origen de la imagen y culto a Nuestra Señora de Guadalupe del Tepeyac, México, UNAM, 1991, pp. 60 y 61. Francisco Miranda Godínez, Dos cultos fundantes: Los Remedios y Guadalupe (1521-1649). Historia documental, Zamora, El Colegio de Michoacán, 2001, pp. 21 y 233.

${ }^{28}$ Sigaut, José Juárez ..., p. 212.
} 
náhuatl publicada por el bachiller Luis Lasso de la Vega, luego el texto histórico-científico del bachiller erudito Luis Becerra Tanco, y el del jesuita Francisco de Florencia. ${ }^{29}$

De acuerdo con Florencia, en La estrella del norte, ${ }^{30}$ el primer traslado de la Virgen de Guadalupe se hizo de la ciudad de México a su ermita, la procesión fue acompañada del esplendor y decoro correspondientes: la imagen bajo palio, los indios con sus vestidos de plumas, la presencia de la luz verdadera a través de las ceras y hachones, la música y los mitotes. Después, por decisión del arzobispo y en conformidad con el virrey Marqués de Cerralbo, el 25 de septiembre de 1629 la imagen de Guadalupe fue colocada en una canoa, al igual que la comitiva, para trasladarse de su ermita a la ciudad de México, con la finalidad de aclamar el cese de la inundación, ahí estuvo hasta el 14 de mayo de 1634, cuando el arzobispo Manzo y Zúñiga la llevó al Tepeyac. ${ }^{31}$ Con tal motivo y conforme a la costumbre, la procesión que acompañó a la imagen salió de la catedral hasta la iglesia de Santa Catalina, en las calles se dispusieron enramadas, con flores, frutos y aves, entre otros adornos que acostumbraban los indígenas. ${ }^{32}$ Con similar ajuar los muiscas en el nuevo Reino de Granada recibieron la imagen de la Virgen de Chiquinquirá en Bogotá, en 1633, cuando fue trasladada de su lugar de origen, Chiquinquirá (vía Tunja); también en el siglo XVII cuando llevaban la imagen en recorridos procesionales en la plaza de Chiquinquirá cada siete años y era colocada en las capillas Posas de la plaza, igualmente el esmero de la fiesta era mayor pues se aderezaban cuatro altares, costeados por los

${ }^{29}$ De la Maza, op. cit., pp. 34, 38 y ss. Miguel Sánchez, Relación de la milagrosa Aparición de Nuestra Señora de Guadalupe de México, en De la Torre Villar y Navarro, op. cit.

${ }^{30}$ Ibid., pp. 376 y 377.

${ }^{31}$ Rubén Vargas Ugarte, Historia del culto de María en Iberoamérica y de sus imágenes y santuarios más celebrados, $3^{\mathrm{a}}$ ed., Madrid, Talleres Gráficos Jura, 1956, vol. 1, p. 192, la comitiva y canoas llegaron a la iglesia de Santa Catalina y al otro día a la catedral. Xavier Noguez Ramírez, Documentos guadalupanos. Un estudio sobre las fuentes de información tempranas en torno a las mariofanías en el Tepeyac, México, FCE/El Colegio Mexiquense, 1993, p. 120, apud Navarro de Anda.

${ }^{32}$ Ibid., p. 120, apud Cayetano Cabrera y Quintero. 
curas de cuatro pueblos, el ornato que portaban los arcos incluía "mucha variedad de frutas, aves, y animales, en que se ven Leones, Osos, Tigres, y Venados, con otras especies, que solicitan para mayor celebridad de esta fiesta". ${ }^{33}$

Ahora bien, respecto a la Virgen de Guadalupe, Lasso de la Vega en calidad de capellán del santuario de Guadalupe "hizo pintar el primer ciclo aparicionista que decoró los muros que protegían el manantial conocido luego como el Pocito en 1648". ${ }^{34}$ Otro tipo de testimonios plásticos, como fuente de información de los milagros de la imagen benéfica hacia su pueblo y la respuesta de éste ante su culto, son tres monumentales representaciones pictóricas a las que remito sumariamente. La primera, intitulada "Traslado de la imagen de la Virgen de Guadalupe a la primera ermita y representación del primer milagro”, ca. 1653, atribuida a José Juárez y su taller, ${ }^{35}$ es junto a las obras escritas un elemento clave de la construcción del culto guadalupano. La supuesta presencia de Zumárraga y el milagro de la resurrección de un indio, después de haber muerto a causa de un flechazo accidental, son elementos clave para exaltar la antigüedad de esta imagen poderosa. En palabras de Sandoval: “Además de ser un cuadro que enaltece el poder milagroso de Guadalupe, eleva la condición beneficiaria de los indios y su participación como fundadores de la tradición"; 36 además de la presencia de las autoridades religiosas y civiles, entre los asistentes resaltan los indígenas aún más, por sus atavíos y por la serie de escenas simultáneas que expresan su forma de religiosi-

${ }^{33}$ Pedro de Tobar y Buendía (OP), Verdadera histórica relación del origen, manifestación y prodigiosa renovación por sí misma y milagros de la imagen de la Sacratísima Virgen María Madre de Dios Nuestra Señora del Rosario de Chiquinquirá, edición facsimilar de la primera edición de 1694, Bogotá, Instituto Caro y Cuervo, 1986, pp. 151 y 152. Véase también Vences, "La Virgen de Chiquinquirá...", vol. 1, p. 345.

${ }^{34}$ Sigaut, José Juárez ..., p. 212,

${ }^{35}$ Noguez, op. cit., pp. 111-121, traslado en 1533 según el cuadro, autores del siglo XVII manejan los años 1531 y 1532; Cuadriello, “Tierra de prodigios...", pp. 180-227. Sigaut, José Juárez ..., pp. 209-224. Tanto esta pintura como la siguiente pertenecen a la Basílica de Guadalupe.

${ }^{36}$ Martha Sandoval Villegas "La devoción y el culto de los indios a la Señora del Tepeyac. Una República elegida por la Reina del Cielo”, en Sigaut, Guadalupe arte..., vol. 1, p. 160. 
dad: vestidos "de caballeros de las milicias aztecas [...] dos ancianos, con coronas florales de romería y un bezote, uno de ellos identificado como el señor de Azcapotzalco, Francisco Plácido, tañe con sus baquetas el teponaxtli [...] al tiempo que entonan sus cantares memoriosos".37

La segunda pintura expone visualmente la "Procesión franciscana de Tlatelolco al Tepeyac implorando la intercesión de la Virgen de Guadalupe para aplacar la peste de cocolixtli de 1554", también ha sido atribuida al taller de José Juárez, ca. 1653-1655. Es la representación del segundo milagro en donde nuevamente se exalta a los beneficiados - los indígenasquienes llegan ante ella a través de una dura disciplina de sangre por parte de niños y adultos. Previa a esta memoria histórica que señala la devoción indígena en relación a la Virgen de Guadalupe, ya los españoles habían sido representados en la obra de Stradanus (1615), ante estas plasmaciones irrefutables, Sigaut afirma: "donde los beneficiarios son españoles, es evidente que un nuevo grupo criollo-mestizo llegaba al punto de querer contar su versión de la historia". ${ }^{38}$ La recuperación de la salud y el libramiento de otros males es el tema de los registros de los favores en el grabado arriba citado, asociados unos a las propiedades curativas del agua del pocito o del aceite de la lámpara, así como a la realización de novenas. ${ }^{39}$ Leyendas estereotipadas que también se utilizaron en las descripciones de favores de El Quinche y Chiquinquirá, como en muchas otras devociones marianas.

La tercera obra "Traslado de la imagen y estreno del santuario de Guadalupe", 1709, está firmada sólo con el apellido Arellano. ${ }^{40}$ Una de las

${ }^{37}$ Ibid., apud Cuadriello, "Tierra de prodigios...", p. 195.

${ }^{38}$ Sigaut, José Juárez..., p. 214, esa forma doliente de rogar clemencia fue prohibida desde el siglo XVI y queda como testimonio plástico de las referencias en las crónicas del siglo anterior.

${ }^{39}$ Godínez, op. cit., p. 344, apud Chauvet.

${ }^{40}$ Rogelio Ruiz Gomar, "Pintura religiosa de los siglos XVII y XVIII", en México en el mundo de las colecciones de arte, Nueva España 1, México, 1994, pp. 236 y 237. Joaquín Berchez, ficha de catálogo número 3, en Los siglos de oro en los virreinatos de América 1550-1700, Madrid, 1999, pp. 149 y 150, registra como autor a J. Arellano acorde a la inscripción en el lienzo. 
manifestaciones de la religiosidad del pueblo en torno a su imagen sagrada por excelencia, además del ritual ordenado y jerárquico de los asistentes señalado por los eclesiásticos, es la presencia de la música, el canto y, por supuesto, las danzas. En las pinturas citadas como en otras descripciones literarias hay registro de estos complementos festivos que en el mundo americano tuvieron un importante desarrollo. En el caso novohispano, especialmente la danza llamada mitote, que se llevaba a cabo por los indígenas en la fiesta a la Virgen. Estas manifestaciones forman parte del repertorio que regionalmente enriqueció a las tradicionales procesiones en un camino barrido, con arcos de juncia y ramilletes de flores a la usanza medieval, pero también práctica análoga entre algunos de los pueblos antiguos de América registradas para el caso novohispano por el dominico Diego Durán.

La celebración de la octava, la procesión y la fiesta en septiembre de 1566, fue con motivo del suntuoso regalo que el rico minero don Alonso de Villaseca donó al culto de la Virgen de Guadalupe, una efigie toda de plata. Un testimonio indígena puntualiza "hubo allá danza; el canto de los Pescados, lo cantaron los mexicanos y los Tlatilolcas el canto de Guerra". ${ }^{41}$ Pero también los cantares de contenido devocional a la guadalupana, que acompañaban al mitote: “esto se corrobora con el pregón del Atabal, antiguo poema náhuatl de tradición guadalupana". ${ }^{42}$ Estas particularidades no las he encontrado en relación con la participación indígena en los otros dos cultos estudiados; por ejemplo en Chiquinquirá, además de la mención de danzas, lo más novedoso como parte del adorno de los arcos y bóvedas de follaje fue la presencia de frutos y ani-

\footnotetext{
${ }^{41}$ Sandoval, op. cit., p. 157, apud Solange Alberro. De la Maza, op. cit., p. 24, vista por el pirata Phillips, dos años después. Cfr. Vargas Ugarte, vol. 1, p. 189, apud García Icazbalceta.

${ }^{42}$ Sandoval, op. cit., pp. 158, 161 y 162, el mitote no era exclusivo de la fiesta a Guadalupe; respecto al Pregón, De la Maza, op. cit., p. 23, explica que fue el padre Mariano Cuevas quien le dio ese nombre al cantar indígena de finales del siglo XVI; Noguez, op. cit., p. 118, sobre la mención por vez primera del mitote a cargo de Becerra Tanco (1666 y 1675).
} 
males. En el caso de Oyacachi, dadas las ceremonias sospechosas que aún a finales del siglo XVI y principios del siglo XVII realizaban sus habitantes, ${ }^{43}$ se debió haber vigilado más sus manifestaciones de religiosidad; aunque no faltaron al día siguiente de la fiesta la diversión hispana de los toros, los juegos de cañas y los saraos. ${ }^{44}$

De la llamada fiesta grande que los indios tenían en relación a Guadalupe del Tepeyac, se celebraba entre el 20 y 30 de noviembre, Sandoval ha establecido una interesante relación con la festividad de la Presentación de la Virgen en el templo - el 21 de noviembre - y las prácticas rituales de los indios hechos en esa festividad. ${ }^{45}$ Cabe recordar que la festividad de la Virgen de El Quinche se cambió a esa fecha porque no se la podía celebrar en el día de la Candelaria - fiesta de guardar entre los indios - por el insufrible clima y condiciones para llegar a Oyacachi, por ello también se trasladó la imagen al pueblo de El Quinche. Ambos casos, por la festividad y la titularidad, en uno y otro, revelan de algún modo el cuidado de las autoridades de orientar el culto a la Virgen María en los días señalados para su festejo, más aún en el marco del restablecimiento, en el calendario, de la fiesta de la Presentación de la Virgen, como ya he referido ampliamente.

Las pinturas anteriormente mencionadas forman parte de una serie visual que difundió y afianzó una tradición, así como el culto interno y externo. Sobre esto último también son reveladoras otro tipo de noticias, una de 1600 sobre la existencia de pinturas de la Virgen de Guadalupe en manos de indios en sitios cercanos al santuario, como el barrio de Tlatelolco (D. F.) y en el barrio de Ecatepec (Estado de México). ${ }^{46}$

Respecto a la Virgen de Chiquinquirá si bien hay una buena cantidad de información respecto a sus traslados y procesiones, al parecer no se

\footnotetext{
${ }^{43}$ Vences, "Una imagen mariana...", p. 55.

${ }^{44}$ Manuel María Pólit Moreno, "Un manuscrito inédito acerca de Nuestra Señora del Quinche", Boletín Eclesiástico. Revista de la Arquidiócesis, t. XXXIX, núms. 8-9, Quito, Imprenta del Clero, agosto-septiembre, 1932, p. 456.

${ }^{45}$ Sandoval, op. cit., pp. 171 y 172.

${ }^{46}$ Ibid., pp. 156 y 157 .
} 
conservan las pinturas que adornaron la iglesia barroca. De ellas el cronista dominico Tobar y Buendía comenta brevemente la cantidad de pinturas al respecto: "y en el cuerpo de la Iglesia, 34 grandes lienzos, en que están pintados treinta y cuatro grandes milagros, de los que ha hecho esta Soberana Señora". ${ }^{47}$ Pero, al describir los milagros ocurridos, en varios ejemplos anotó que para memoria del favor se hizo un lienzo que se halla en el interior del santuario, de los cuales citaré los más novedosos respecto a la información que tiene parecido con las otras dos advocaciones. El que se cita como el primer milagro, se plasmó en una pintura que ejemplifica el arrepentimiento de la vida pecadora que llevó una joven hermosa de nombre Catarina García — natural de la ciudad de Mariquita - a la que apodaron el Ángel del río Gualy, "cual otra Magdalena" renunció a lo mundano y material para ofrendar su vida penitente a la Virgen; don Francisco cacique de Tussa fue librado de la muerte por garrote, pues en la boca le protegía una medalla de la Virgen; un residente del puerto de San Lúcar de Barrameda invocó a la Virgen cuando fue atravesado con la espada por unos ladrones y salvó la vida, hizo peregrinación y rezó las novenas. ${ }^{48}$ Otros, fueron los típicos libramientos de la muerte por enfermedad, por la caída de un caballo o en una construcción, picadura de serpiente, cautiva entre indios belicosos, ahogado, ataque de animales, rayos, algunos salvados por traer una medalla de la Virgen; todo ello sucedido a pobladores de distintas ciudades del nuevo Reino de Granada. Las pinturas debieron ser interesantes además por la descripción del entorno natural en donde acontecieron la mayoría de los favores.

Una modesta representación pictórica, idealizada, de lo que debió ser la capilla de la "renovación de la imagen" es la que se presenta en la sección inferior de un grabado novohispano de la segunda mitad del siglo XVIII, ${ }^{49}$ se incluye este elemento para redondear el respaldo visual

\footnotetext{
${ }^{47}$ Tobar, op. cit., p. 147.
}

${ }^{48}$ Ibid., pp. 168 y 169; pp. 194, 242 y 243.

${ }^{49}$ Magdalena Vences Vidal, La Virgen del Rosario de Chiquinquirá, Colombia: afirmación dogmática y frente de identidad, México, Museo de la Basílica de Guadalupe [en prensa]. 
de una imagen que a sus devotos y peregrinos procura la salud. Respecto a la representación plástica de las procesiones en las ciudades de visita, cito como ejemplo la que se llevó a cabo en Tunja en 1587, cuando se trasladó la imagen para darla a conocer e implorar misericordia a causa de los efectos negativos de una peste..$^{50}$

En relación a la Virgen de El Quinche, el traslado más importante fue con motivo de su cambio de sede, de la población de Oyacachi a la de El Quinche (distante unas ocho leguas), de un lugar internado de difícil acceso a un sitio definitivamente ventajoso en muchos aspectos materiales, humanos y clave en la red de comunicación cultural del incanato - caminos aprovechados en la época colonial- , aspectos todos ellos que garantizarían el desarrollo del culto, aunado a que desde 1591 cuando la imagen fue adquirida de manos de Diego de Robles, inmediatamente, se dice, empezó a realizar prodigios. Entre sus cronistas se cuenta al cura beneficiado Diego de Londoño (su capellán en 1601), el bachiller Miguel Sánchez Solmirón (autor de un texto de 1640 sobre la referida advocación), Diego Rodríguez de Ocampo (1650); por otra parte los llamados "apóstoles de la Virgen de El Quinche" fueron aquellos que promovieron desde Quito las romerías y que acopiaron la limosna para la construcción de la capilla en Oyacachi y su ajuar para la liturgia, entre ellos estuvo el padre Fernando de Cisneros y Pedro de Balenzuela - a quien correspondió celebrarla con decoro en el día de la Presentación de la Virgen y organizar la cofradía.

Los autores mencionados describieron algunos pormenores de los prodigios ocurridos en torno a esta imagen mariana, patrona de Ecuador, conforme a una serie de estereotipos: el canto de unas aves en la noche, éstas "eran del tamaño de una golondrina con unas cruces blancas en los pechos"; la luz que caía del humilde techo de paja de la capilla; el tañido nocturno de las campanas que anunciaba la muerte de un indio; escampaba la lluvia cuando la sacaban en procesión; llegaba con los pies enlodados; el rostro le cambiaba de color, etc. También los devotos empezaron

${ }^{50}$ Vences, "La Virgen de Chiquinquirá...", vol. 1, pp. 336-342. 
a mostrar su religiosidad a través de la romería, la celebración de novenas y las procesiones en la plaza con la alegría de los arcos y los castillos.

Por decisión del obispo fray Luis López de Solís, el 10 de marzo de 1604 el padre Diego de Londoño llevó a cabo el traslado de la imagen de la Virgen de Oyacachi a su nueva iglesia, acompañada de los elementos tradicionales y simbólicos del manejo decente de las imágenes sagradas: cruz y pendones, hachas encendidas, la presencia de españoles y más de cien indígenas procedentes de El Quinche, todo ello solemne y festivo con la algarabía de la asistencia y los instrumentos musicales. En determinados puntos del recorrido se instalaron unas estaciones con colgaduras a manera de dosel, cera encendida y música para recibirla adecuadamente. ${ }^{51} \mathrm{~A}$ ese nuevo sitio se dirigieron las romerías, de ahí sacaron la imagen para después llevarla a Quito (a 6 leguas) con la finalidad de pedir su intercesión para cesar enfermedades (1634, la de tabardillo) pestes, tempestades y hasta pedir la lluvia ante una sequía muy prolongada. En el trayecto a la ciudad de Quito no faltó el recibimiento con el adorno clásico de arcos hechos de tela, el sonido de la música, las banderas sostenidas en altas cañas, el rezo del rosario y la letanía en coro. Carlos Sono detalla que "en el ejido, que se halla a las afuera de Quito, la aguardaban el Cabildo con su venerable prelado al frente, el Clero, las comunidades religiosas, los gremios todos y las tropas formando larga calle en dos alas divididos, con las músicas militares, y más de dos mil alumbrantes", 52 una vez que se disponía a entrar a la ciudad, la imagen era conducida en hombros "de las más distinguidas matronas de la Capital", por supuesto como en la procesión citadina, las calles también estaban adornadas, los balcones colgados y la lluvia de flores caía a su paso solemne y piadoso.

De su intercesión ante las pestes del siglo XVII dan testimonio las Actas del cabildo: de viruela en 1648 queda plasmada memoria en un lienzo y

${ }^{51}$ José María Vargas (OP), Patrimonio artístico ecuatoriano, Quito, Santo Domingo, 1972, p. 351.

${ }^{52}$ Carlos Sono, Historia de la imagen y del santuario del Quinche, $2^{\mathrm{a}}$ ed., Quito, 1903 (la primera de 1883), pp. 78 y 79. 
su inscripción, cuya hechura patrocinó el canónigo de la catedral de Quito, Manuel Morejón; ${ }^{53}$ otras visitas se sucedieron por diversas enfermedades en 1667, 1672-1674, 1677, 1691; la debacle y concentración de pestes en $1693 .{ }^{54}$ El cabildo la juró por patrona de la ciudad de Quito, en 1698, en los devastadores terremotos de Latacunga y de otras poblaciones; este amparo fue ratificado en 1757, para entonces el patronímico de El Quinche ya había prevalecido sobre el de su sede originaria, Oyacachi.

Las pinturas que se conservan en el actual santuario de El Quinche, con el tema de los milagros de la Virgen de esa advocación, son, al igual que las anteriores advocaciones, obras posteriores — de mediados del siglo XVII- que se mandaron hacer con similar cometido de las de Guadalupe y de Chiquinquirá, dejar memoria visual de la antigüedad de los favores otorgados y de su presencia entre los habitantes de un determinado territorio. A esa época corresponde el inicio de un afianzamiento del culto a las tres imágenes. De modo tal que se produjo una recreación pictórica de varios milagros, colocadas las pinturas en los muros laterales de la que fuera la iglesia barroca "un templo muy especial" registra el jesuita Bernardo Recio a raíz de su visita en 1754. Todavía el padre Sono conoció esa iglesia que fuera afectada y después derruida por los terremotos de 1859 y 1868, en su escrito hay descripción de los lienzos. ${ }^{55}$ Los primeros milagros ocurrieron en el bosque de alisos en ocasión del corte de madera para la construcción de la capilla de la Virgen de Oyacachi, el primero que cita es aquel testimonio plástico que refiere cómo el indio Francisco Guacán fue librado de la muerte cuando cortaba un árbol; otro muy afamado es el del hijo de la india Marta Sumanguilla, a punto de ser devorado por un oso; de otra temática es aquel que refiere cómo la Virgen acoge en su brazo a una niña que resucitó (teniendo en el otro a su Hijo); otro lienzo registra cómo al salir la imagen en procesión, el día de su fiesta, la lluvia intermitente cayó fuera del área en que

\footnotetext{
${ }^{53}$ Vargas, op. cit., p. 356. Sono, op. cit., pp. 127 y 128, en seguida describe otro lienzo de similar tema, "más sonado y moderno".

${ }^{54}$ Vargas, op. cit., p. 357. Sono, op. cit., pp. 129-132.

${ }^{55}$ Vargas, op. cit., p. 354.
} 
se realizaba el recorrido. Una pintura más rememoraba el premio que le dio la Virgen a una mujer que le llevó donativos y de realizar un largo camino desde Popayán se encontró con la iglesia cerrada; desconsolada se echó de rodillas, entonces las puertas se abrieron, entró y la imagen se dejó ver en su nicho al levantarse el velo que la cubría. Un prodigio de extrema ternura es el de un hombre pobre que tocaba el arpa para celebrar a la Virgen, cuyo esqueleto intacto mostraba las manos "incorruptas y frescas". 56

Se conserva un cuadro de Joaquín Pinto sobre el libramiento de la muerte al escultor Diego de Robles cuando atravesaba un puente y cayó del caballo. Una constante en la serie de pinturas que exponen los favores de la Virgen del Quinche es la recreación del paisaje exterior en donde se localizaba la primera población y ermita de Oyacachi (que no es la actual) a tres mil metros de altura en una estrecha meseta rodeada de bosques y enmarcada por las montañas de la tercera cordillera donde se asienta, hay así una estrecha conexión entre la imagen sagrada y el territorio que sacralizó, como si se expresara la gran protección que ella tuvo a su cargo en esa región inhóspita poblada por sus primeros devotos. Dos de los lienzos recordatorios incluyen a los donantes agradecidos por algún favor, los otros tres evocan milagros y son interesantes también por lo anecdótico de los casos, el de la corrida de toros que rememora el milagro de 1660 sobre el párroco Juan de Cepeda, es obra del jesuita Nicolás Javier Goríbar; un par de lienzos de cierta extensión incluyen a la ciudad de Quito. ${ }^{57}$

El preludio de lo "barroco" americano se concreta en los ajuares enviados a la Virgen de Guadalupe de Extremadura, a la Virgen de la Antigua de Sevilla, al Cristo de Burgos y a otros, este suntuoso y colorido regalo hizo su aparición muy tempranamente en España, apenas dos años después de consumada la conquista de México-Tenochtitlan. Entre los

${ }^{56}$ Sono, op. cit., pp. 13 y 14; 16-18; 24-27; 87-90; 96 y 97; etc.; p. 54, los lienzos estuvieron colocados en orden cronológico, los ocurridos en Oyacachi y luego los de El Quinche,

${ }^{57}$ Vargas, op cit., pp. 336-366, Goríbar fue discípulo de Miguel de Santiago. Sono, op . cit., p. 84. 
objetos y ajuares de plumaria que Hernán Cortés envió al emperador Carlos V, cobra significado el registro de los regalos confeccionados por los amantecas a cargo de este tipo de objetos suntuarios - con materiales preciados sólo usados por la nobleza: oro, plumas y piel—, los lotes fueron destinados a resaltar la dignidad de una serie de imágenes de culto ibéricas, simbólicamente a todas se les integró un elemento defensivo, signo de la preeminencia y del poder de las mismas. A la que empezaban a saber que era la Madre del verdadero Dios, a Guadalupe de Extremadura se le destinó un vestuario que consistió en

un plumaje a manera de capa, el campo verde y la orladura de plumas verdes largas, el cabezón labrado de oro y pluma azul aforrado con un cuero de tigre. Ítem, un corse(le)te de pluma azul y oro, abierto por los pechos, a manera de sacrificado al uso que acá se sacrifican, con la cintura de pluma verde. Ítem, una rodela, el campo azul con un hombre figurado en medio labrado de oro. ${ }^{58}$

Como bien se conoce la presencia de ajuares propios de la tierra fueron intercalados con la moda europea en las representaciones pictóricas de la pintura barroca desde el siglo XVII.

\section{LA CULTURA BARROCA}

Sánchez Herrero, como otros autores, ha llamado la atención sobre la aplicación del concepto de "barroco" fuera de la temporalidad del arte de la Contrarreforma. Señala contundentemente "Andalucía es barroca con anterioridad a que el barroco exista". Esta afirmación parte de una manifestación cultural especialmente asociada a una identidad étnica en una región, y además como manifestación de religiosidad popular en los siglos XIII al XV. El ejemplo utilizado por el autor, para describir los elementos que constituyen lo barroco en una manifestación religiosa, es la recepción de los reyes en Sevilla ocurrida en los años de 1327 y 1340,

${ }^{58}$ Ramírez, op. cit., t. II, p. 668, ca. 1523. 
acerca de la que opina "En dicha recepción encontramos todos los elementos que hoy siguen estando presentes en un desfile procesional de Semana Santa o del Corpus: el palio, el incienso, las calles enramadas, los balcones adornados, la gente, etc." ${ }^{59}$ Aunque sin duda, ese antecedente y las manifestaciones externas de religiosidad de siglo XVI son el preámbulo del barroco del siglo XVII. ${ }^{60} \mathrm{El}$ medio de plasmación es el arte pero, además, hubo todo un marco ideológico que definió a esa época y a las manifestaciones culturales, la Contrarreforma.

¿Cómo se ha definido lo barroco por los elementos que contiene? Color, expresión retórica y visual, teatralidad, exaltación de los sentidos (visual, auditiva, olfativa), mediante el recurso del realismo que incita a lo táctil, a lo humano que ensalza y tiende a obtener la gloria con Dios. El arte va dirigido a los sentidos y a lo sensorial, no a la razón. ${ }^{61}$

En una medida similar, este tipo de elementos se encuentran también en la religiosidad de diversos grupos étnicos en México, en Perú, Colombia, y que desde finales del siglo XVI tuvieron un acoplamiento con las prácticas medievales, en el uso de pebetes o sahumerios con pastillas o copal que desprenden buen olor, enramadas de flores y aves para adornar que otorgan frescura, aroma y alegría multicolor; el uso de la madera policromada en forma de arcos y bóvedas para realzar el camino procesional, la actitud respetuosa y festiva o bien doliente de la asistencia, según el tipo de mecanismo de vivir la religión, rogativa para aclamar el cese de las enfermedades y desastres naturales, el traslado de la imagen en la construcción de identidad, las procesiones en el día de la fiesta.

Andalucía también ha sido el centro de un marcado culto a la diosamadre, hasta la actualidad, de donde se desprenden formas particulares. De acuerdo a Domínguez Morano citado por Sánchez Herrero:

${ }^{59}$ Sánchez Herrero, “Algunos elementos...”, p. 299.

${ }^{60}$ Ibid., pp. 299, 303 y 304, "el pueblo andaluz y el del mediterráneo son dados a manifestaciones extrovertidas y lúdicas... en tanto que la religiosidad castellana, se tiñe de barroquismo".

${ }^{61}$ Jorge Alberto Manrique, "La fe en la forma según el Concilio de Trento", Ars Auro Prior Studia IoanniBíalostocki, Sexagenario Dedicata, Varsovia, Panstwowe Wydaunictwo Naukawe, 1981, p. 771. 
La íntima conexión entre la diosa-madre y la naturaleza posee indudables paralelismos con la estrecha relación que también se ha establecido entre María y la fecundidad de la tierra. Los santuarios marianos como los de la diosa-madre se sitúan en parajes privilegiados por la naturaleza, frecuentemente al lado mismo de un pozo o un manantial, y no raras veces rodeados de leyendas que hablan de la fecundidad milagrosa de la tierra. ${ }^{62}$

Las cualidades benéficas del agua asociadas a los cultos de la Virgen del Quinche, Chiquinquirá y Guadalupe. Las preguntas latentes ¿estos cultos originarios están preñados de creencias nativas o son su continuidad bajo otro rostro, hubo una coexistencia, se borró con las efigies de la Virgen María todo vestigio antiguo, o podemos hablar mejor de fusión y adopción de modelos rituales a los cultos y rituales cristianos? Entre la manifestación externa de los pueblos del mediterráneo y los de América Antigua en su relación con el territorio, la diferencia es nítida.

La religiosidad en torno a una imagen sagrada llegó a Hispanoamérica al final del reinado de los Reyes Católicos, seguido de la monarquía de Carlos I de España y emperador V de Alemania en donde hay que considerar las improntas alemanas, flamencas y de los Países Bajos. Esta gran herencia cultural fue percibida, aceptada y decantada, como parte de un proceso de implementación, apropiación y transformación; posteriormente amalgamada con las tradiciones culturales americanas insertas en un repertorio de creencias ancladas en los ciclos naturales, como siglos atrás había sucedido con las culturas mediterráneas. En los tres lugares que me ocupan especialmente, se vivió una religiosidad hispana (caste-

${ }^{62}$ Ibid., p. 302, hay que tener presente que en el siglo XIII Andalucía se castellanizó: lengua, instituciones, costumbres y sangre, de modo tal que "la religiosidad cristiana popular andaluza de la baja Edad Media, siglos XIII al primer tercio del siglo XVI, está enmarcada dentro de la religiosidad castellana de la misma época. Todas las manifestaciones de la religiosidad bajo medieval andaluza, aun aquellas que puedan parecer más típicas, tienen un antecedente, son prolongación o un doble de la castellana"; ni en toda Castilla ni Andalucía se celebraba la Semana Santa con "procesiones, cofradías y disciplinantes hasta finales del XV o primeros años del XVI". 
llanizada como la lengua), ${ }^{63}$ se experimentó y se apropió por la complejidad étnica y cultural en el proceso de construcción de la América Latina.

La cultura barroca en Hispanoamérica es, por un lado, la gran herencia de los reinos y pueblos constituyentes de la monarquía hispánica y, por otro, la apropiación y pertenencia de la herencia de dos mundos culturales, lo que de las fórmulas europeas hicieron los criollos, los indígenas, los mestizos y castas, que sostuvieron y mantuvieron el "reino de Dios", al mismo tiempo que reivindicaban un pasado americano. Acorde a la opinión de Escandón: España que "generó y luego transmitió a sus dominios ultramarinos esta cultura de apego a la tradición y de peculiar religiosidad". ${ }^{64}$

La cultura barroca comprende lo ideológico visual incentivado por lo retórico auditivo, aunque entre los grupos humanos dominó la aceptación, entendimiento y ante todo la percepción de lo primero. El arte fue el medio eficaz de afirmación y exaltación de dogmas, dio respuesta a la manifestación de los sentimientos humanos; a través de las composiciones y expresiones formales se llevó a cabo la finalidad de conmover con alegría, dulzura, ternura, dolor y se convocó a la piedad. En opinión de Sánchez Lora:

La cultura barroca no está pensada para el intelecto, pues no pretende convencer, sólo mover conductas conmoviendo, sacudiendo la sensibilidad emocionando, y nada emociona más que lo que entra por los ojos, como ya prescribieran Aristóteles y Horacio. Por ello toda la batería apunta a entrar con artificio, a impactar deslumbrando al ojo, forzando a hacer ver. ${ }^{65}$

${ }^{63}$ Parcialmente como sucedió la aceptación y apropiación de la religiosidad castellana en Andalucía, en el siglo XIII, pues sufrió "una modificación, de matiz, de carácter, sencillamente pasa a ser algo castellano, pero traducido, expresado, vivido por las gentes andaluzas", en ibid., p. 302.

${ }^{64}$ Patricia Escandón, "La cultura barroca en Indias: la visión de Mariano Picón Salas", Latinoamérica. Revista de Estudios Latinoamericanos, núm. 42, México, CCyDELUNAM, 2006, p. 37.

${ }^{65}$ José Luis Sánchez Lora, "Barroco y simulación: cultura de ojos y apariencias, desengaño de ojos y apariencias", en Pedro Chalmeta, Fernando Checa et al., Cultura y culturas en la historia. Quinientas Jornadas de Estudios Históricos, Salamanca, Universidad de Salamanca-Departamento de Historia Medieval, Moderna y Contemporánea, 1995, p. 75. 
El barroco, y en su definición como categoría o instrumento de estilo sigo y comparto la opinión de Manrique, no es únicamente un estilo artístico, el concepto en efecto involucra otras manifestaciones de la cultura, no sólo lo que llamamos arte, por lo tanto también califica a toda una gran época homogénea, es además "un estilo común de vida" ${ }^{66}$

Sin embargo, no dejo de señalar, y me sumo a otros autores, que la cultura barroca trascendió su época de mayor expresividad en el siglo XVII hasta llegar aun a nuestros días, con una propia tradición seglar y religiosa tal, que se observa en los rituales cotidianos y ceremonias, afirmación que se comprueba por ejemplo en la fiesta del santo patrono de Coixtlahuaca, San Juan Bautista, en la Mixteca alta de Oaxaca, hay ahí como en otras partes de la región un importante despliegue de los usos y costumbres, que se expresan en la jerarquía territorial y humana, en la forma de gobernar con la cooperación de la comunidad en beneficio de las áreas públicas, en los vínculos con la Iglesia a través de las imágenes de mayor devoción; también al interior de los hogares, en la distribución espacial — aparentemente fragmentada — de la casa tradicional (aunque esté construida con materiales modernos) y en el uso de esos espacios para llevar a cabo una serie de ceremonias en momentos importantes de los núcleos familiares. El protocolo y el ritual son fundamentales, parafraseando a Picón Salas, tanto en el "reino del hombre" como en el "reino de Dios", entre la tradición y la modernidad. En modo similar a lo que Escandón ha expuesto sobre otros ejemplos. ${ }^{67}$

${ }^{66}$ Jorge Alberto Manrique, "Barroco mexicano: ¿qué tan barroco? ¿qué tan mexicano?”, Memoranda, núm. 15, año III, 1991, México, Subdirección General de Servicios Sociales y Culturales del ISSSTE, p. 6. Del mismo autor, "La formación de la arquitectura barroca americana", Nuestra América, El barroco latinoamericano, núm. 3, 1980, pp. 81-88.

${ }^{67}$ Escandón, op. cit., p. 36, “A quienes creen que aquello que se dio hace 300 años ha perdido todo su efecto y vigencia, les sugiero que presencien las fiestas del santo patrono en alguna barriada, o que me expliquen, en términos de los usos sociales contemporáneos, los complicados rituales y protocolos de una familia tradicional de Lima o Guanajuato". 
En buena medida la pervivencia de estas conductas sociales se debe a las creencias religiosas que se maceraron desde el mismo siglo XVI con toda una cepa previa de origen medieval. Conforme a lo expuesto ya por varios autores y que retomo para ir cerrando estas reflexiones:

la renuencia de la cultura hispánica a desprenderse de la parte más profunda, del corazón de sus tradiciones - y me refiero en este caso a la religiosa, pero hay otras - , no es una elaboración del periodo barroco, sino un rasgo previo, que bien puede venir de la Reconquista o de la unificación política de la época de los Reyes Católicos; en cualquier caso, tiene un fuerte aroma medieval, que evoca la inmutabilidad de una estructura estamental o jerárquica, cuya cúspide es Dios. ${ }^{68}$

La búsqueda de la cercanía con Dios, de la recepción de los bienes otorgados, en este caso, por imágenes de la Virgen María, generó una serie de ritualidades cuyo fin fue el santuario de veneración - centro, al mismo tiempo que destino y camino hacia lo sagrado — simbólicamente relicario del tabernáculo de Dios, ante la imagen mediadora se imploraba misericordia, se agradecían los beneficios y se le rendía honor. Pero toda esta demostración sirvió también como elemento de cohesión de una comunidad devota, estamentada, de distinta procedencia étnica y vinculada a un territorio; los lazos de identidad se construyeron, además de los traslados de las imágenes y otros mecanismos, mediante la plasmación pictórica de esos recorridos y los favores otorgados, como el testimonio visual más poderoso que garantizara una tradición seglar y eclesiástica, española e indígena, criolla y mestiza alrededor de la devoción a la Virgen de Guadalupe del Tepeyecac, a la Virgen del Rosario de Chiquinquirá y a la Virgen de la Presentación de El Quinche.

Recibido: 15 de agosto, 2008. Aceptado: 17 de enero, 2009.

${ }^{68}$ Escandón, op. cit., p. 41. 